\title{
Reduction of miR-29c enhances pancreatic cancer cell migration and stem cell-like phenotype
}

\author{
Jianxin Jiang ${ }^{1}$, Chao Yu ${ }^{1}$, Meiyuan Chen ${ }^{1}$, Hao Zhang ${ }^{1}$, Se Tian ${ }^{1}$ and Chengyi Sun ${ }^{1}$ \\ ${ }^{1}$ Department of Hepatobiliary Surgery, Affiliated Hospital of Guiyang Medical College, Guiyang, Guizhou, China \\ Correspondence to: Chengyi Sun, email: chengyisun2014@163.com \\ Keywords: Pancreatic cancer, miR-29c, Wnt, FRAT2, LRP6 \\ Received: October 30, $2014 \quad$ Accepted: December 25, $2014 \quad$ Published: December 30, 2014 \\ This is an open-access article distributed under the terms of the Creative Commons Attribution License, which permits unrestricted use, \\ distribution, and reproduction in any medium, provided the original author and source are credited.
}

\section{ABSTRACT}

The hallmarks of pancreatic cancer are limitless replicative potential as well as tissue invasion and metastasis, leading to an extremely aggressive disease with shockingly high lethality. However, the molecular mechanisms underlying these characteristics remain largely unclear. Herein, we report the results of a differential miRNA expression screen that compared pancreatic cancer tissues and normal pancreatic tissues, where the pancreatic cancer tissues had highly downregulated miR-29c with relative Wnt cascade hyperactivation. MiR-29c directly suppressed the following Wnt upstream regulators: frequently rearranged in advanced T-cell lymphomas 2 (FRAT2), low-density lipoprotein receptor-related protein 6 (LRP6), Frizzled-4 (FZD4) and Frizzled-5 (FZD5). Furthermore, transforming growth factor- $\beta$ (TGF- $\beta$ ) inhibited miR-29c expression, leading to Wnt activation. Significantly, our results were consistent with an important correlation between miR-29c levels and TGF- $\beta$ hyperactivation and the activated $W n t$ cascade in human pancreatic cancer specimens. These findings reveal a novel mechanism for Wnt hyperactivation in pancreatic cancer and may suggest a new target for clinical intervention in pancreatic cancer.

\section{INTRODUCTION}

Pancreatic cancer (PANC), which caused 330,000 deaths globally in 2012 [1], has the worst 1- and 5-year survival rates of all cancers. The 1-year relative survival rate for all stages of PANC combined is approximately $25 \%$, and 5 -year survival is estimated as no more than $6 \%[2,3]$. Patients with PANC have poor prognosis and short survival partly because PANC usually causes no symptoms in the early stage, leading to locally advanced or metastatic disease at the time of diagnosis $[4,5]$. Unfortunately, the lack of effective therapy worsens the situation [6]. Therefore, there is an urgent need to design novel strategies for achieving better treatment outcome in patients diagnosed with PANC.

Metastasis and recurrence are the two main causes of cancer-related mortality. An increasing number of observations suggest that the stemness of cancer cells is implicated in tumor progression and metastasis [7-10]. Although a series of studies has proven the cancer stem cell hypothesis in PANC [11-15], the precise molecular mechanisms underlying the stem cell-like properties of PANC cells remain largely unknown. Undercover molecular mechanisms that collaboratively regulate PANC cell metastasis and stemness are expected to provide new insights into the development of novel and effective therapy for PANC. In this context, identifying genetic and/or epigenetic factors that modulate the stem cell-like phenotype of PANC cells is of significant importance in the clinic.

MicroRNA (miRNA) dysregulation is implicated in the development and progression of practically all tumor types [16]. MiRNAs may influence cancer cell stemness particularly by modulating specific pathways [17-20]. The canonical Wnt cascade modulates both self-renewal and oncogenesis in different organs $[8,21]$ and is hyperactive in PANC [22]. Herein, we reveal that following inhibition by transforming growth factor- $\beta$ (TGF- $\beta$ )/Smad3 signaling, miR-29c was remarkably decreased in PANC cells. Reintroducing miR-29c into PANC cells significantly suppressed the PANC cell malignant phenotype and the stem cell-like phenotype by 
targeting Wnt signaling pathway regulators. Furthermore, the xenograft tumor model showed that miR-29c inhibited PANC tumorigenesis in vivo. Our findings reveal a novel pathway by which epigenetic modulation of miR-29c renders the PANC cell abilities of robust self-renewal and aggressive metastasis ineffective.

\section{RESULTS}

\section{Reduced miR-29c levels in PANC correlated with patient prognoses}

We retrieved miRNA expression profiles from two data sets: TCGA and the Gene Expression Omnibus dataset GSE24279 [23], and found that miR-29c was significantly decreased in PANC tissues compared with normal pancreatic tissues. Interestingly, miR-29c was also downregulated in patients who had died from PANC, as well as patients with proven tumor recurrence (Figure 1A). To validate the expression pattern of miR-29c in PANC, quantitative reverse transcription-PCR was conducted on five normal pancreatic tissue samples and 132 frozen PANC samples. MiR-29c levels remained high in grade I tumors but became markedly lower in grade IIb tumors and were further decreased in grade III and IV tumors (Figure 1B). Statistical analysis revealed that miR-29c was associated with shorter overall survival $(P=0.003)$ (Figure 1C). Additionally, miR-29c expression was reduced in the eight PANC cell lines tested compared with that in the normal hTERT-HPNE cell line (Figure 1D). These findings suggest a possible link between miR-29c reduction and human PANC progression.
A

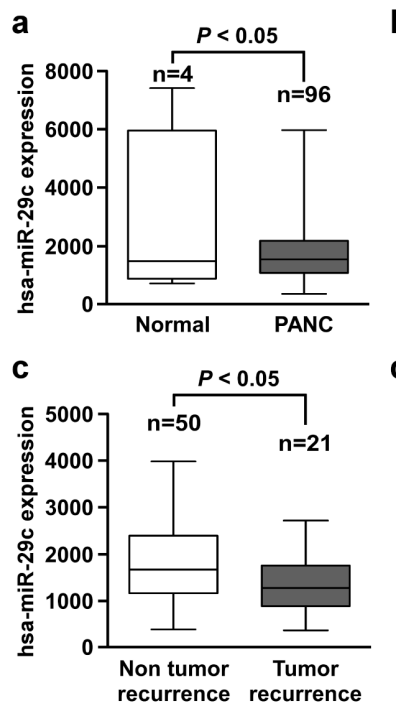

B

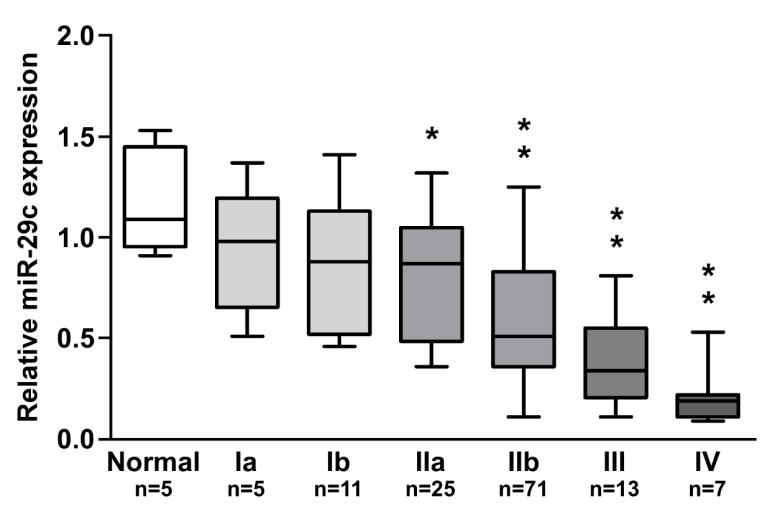

C

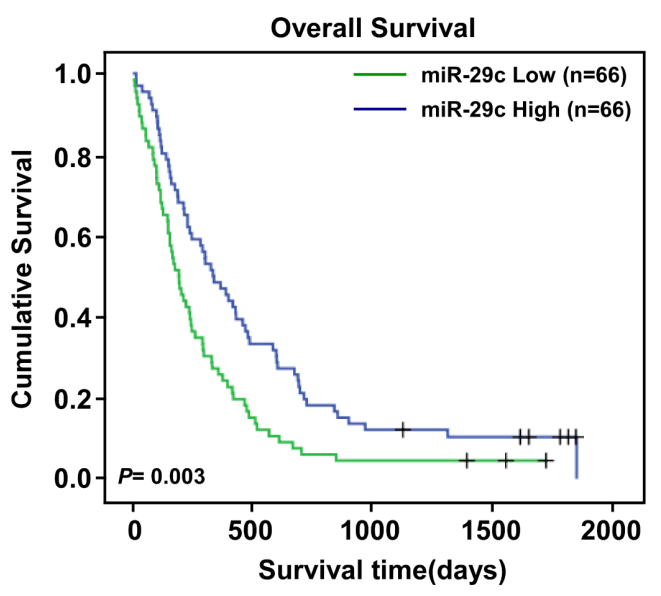

D

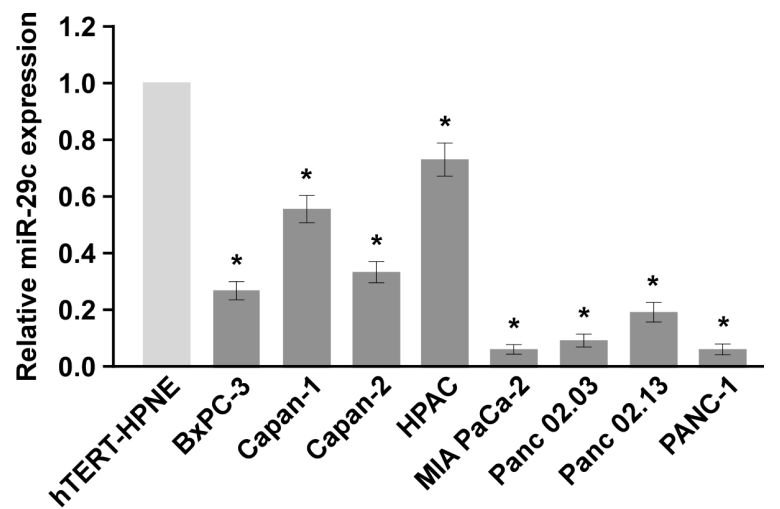

Figure 1: Reduced miR-29c expression in pancreatic cancer with poor prognosis. A, Expression profiles of miRNA were obtained from the TCGA database and the NCBI GEO database. B, Statistical analysis of miR-29c expression in normal pancreas tissues $(n=5)$ and pancreatic cancer specimens of different WHO grades $(n=132)$. C, Kaplan-Meier curves of pancreatic cancer patients with low- versus high-expression of miR-29c $(n=132 ; \mathrm{P}=0.003)$. $\mathrm{D}$, Real-time PCR analysis of miR-29c expression in 8 indicated pancreatic cancer cell lines and normal pancreas cell line hTERT-HPNE. 


\section{Restoring miR-29c suppressed PANC cell migration and invasion and attenuated the stem cell-like phenotype}

We selected the BxPC-3 and Capan-2 PANC cell lines to investigate whether miR-29c could modulate PANC cell migration and invasiveness. A wound-healing assay was used to detect the effect of miR-29c on cell migration. Compared with the negative control \#1 (NC\#1) cells, which spread to the center within 20 hours, miR29c-transfected cells exhibited clearly slower migration and decreased cell spreading (Figure 2A). We used the Transwell invasion assay to determine the effect of miR-29c expression on PANC cell invasion. Compared with the control cells, fewer miR-29c-transfected cells invaded across the Matrigel-precoated membrane (Figure 2B). Significantly, the 3-dimensional spheroid invasion assay revealed that $\mathrm{NC} \# 1$-control cells displayed highly aggressive invasive growth after 7 days, but the miR-29c-
A

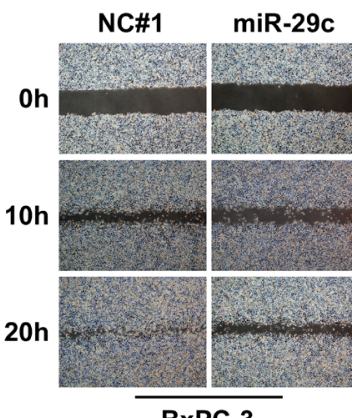

BxPC-3

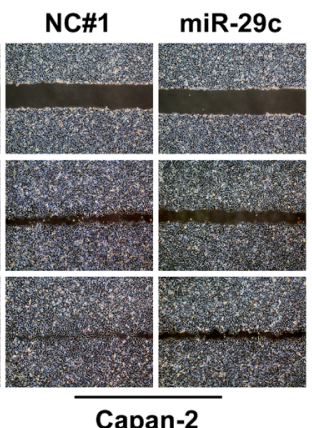

B

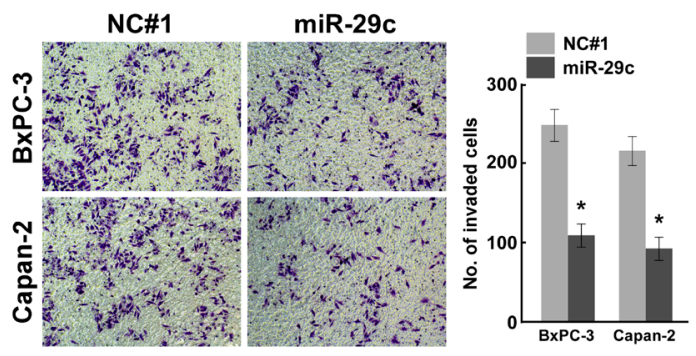

C

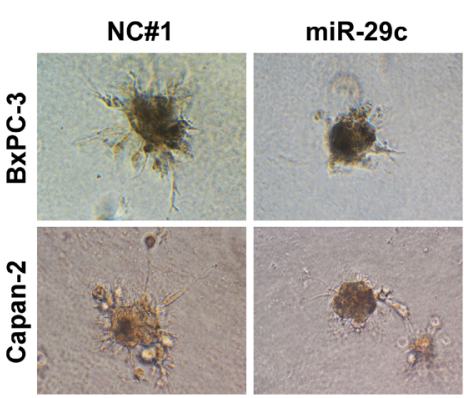

D a

NC\#1

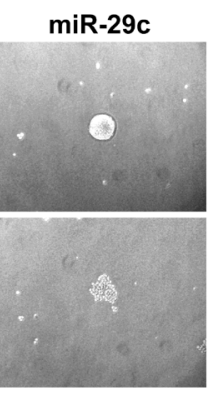

b

$\mathbf{E}$

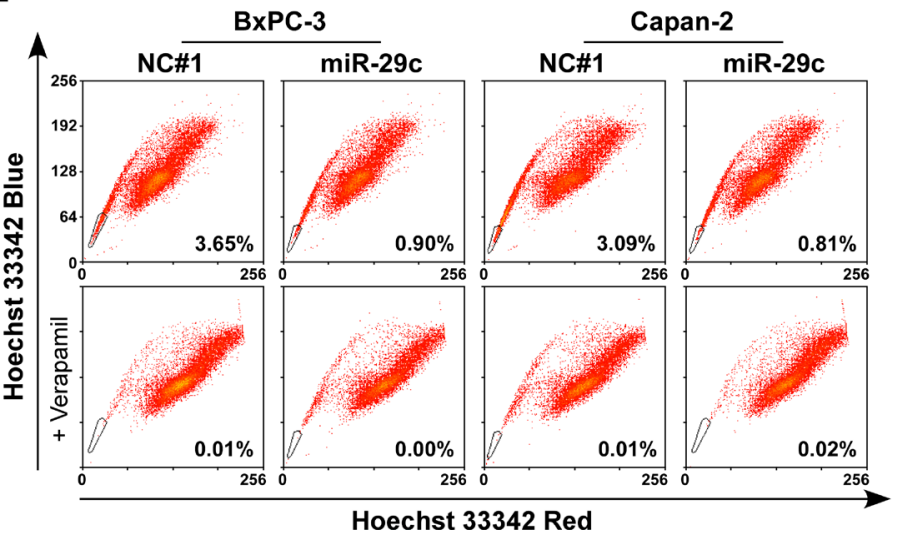

$\mathbf{F}$

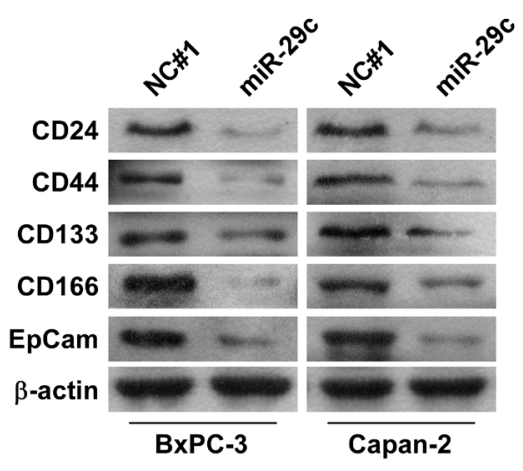

Figure 2: MiR-29c suppresses pancreatic cancer cells migration and invasion as well as attenuates stem cell-like phenotype in vitro. A, Wound-healing assay was conducted with indicated cells and images were taken at 0,10 , and 20 hours. B, Representative images (left) and quantification (right) of penetrated cells were analyzed using the Transwell matrix penetration assay. C, Representative micrographs of indicated cultured cells at day 7 of culture in 3-dimensional spheroid invasion assay. D, Representative images of spheres formed by the indicated cells (left) and histograms showing the mean number of spheres (right). E, Hoechst 33342 dye exclusion assay showing that overexpressing miR-29c attenuated the SP cells in the indicated cells. F, Western blot analysis of CD24, $\mathrm{CD} 44, \mathrm{CD} 133, \mathrm{CD} 166$ and EpCam expression in the indicated cells. $\beta$-actin was used as a loading control. Error bars represent mean $\pm \mathrm{SD}$ from 3 independent experiments; *, $P<0.05$; **, $P<0.01$. 
transfected-cells did not (Figure 2C). Taken together, these findings indicate that miR-29c greatly suppresses PANC cell migration and invasion.

Cancer tends to relapse after surgical resection, and this characteristic is considered mainly ascribable to the stem cell-like properties of a fraction of cells within the tumor [24]. As miR-29c levels are particularly decreased in patients with proven tumor recurrence, we suggest the potential role of miR-29c in the development and maintenance of the stem cell-like property of PANC cells. Compared with control cells, miR-29c-transfected cells formed much smaller spheres after 7 days of culture (Figure 2D). The Hoechst 33342 dye exclusion assay showed that miR-29c overexpression decreased the proportion of side population-positive $(\mathrm{SP}+)$ cells from $3.65 \%$ to $0.90 \%$ in BxPC-3 cells, and from $3.09 \%$ to $0.81 \%$ in Capan-2 cells (Figure 2E). Furthermore, the CD44+ population and the expression of multiple pluripotency-associated factors were dramatically decreased in miR-29c-transfected cells compared with the control cells (Figure 2F). Collectively, our results reveal that miR-29c restoration attenuates the PANC cell selfrenewal ability.

\section{MiR-29c upregulation attenuated tumorigenicity and invasion in vivo}

To understand whether miR-29c is involved in PANC cell tumorigenesis and invasiveness in vivo, we subcutaneously inoculated $10^{3}-10^{6}$ cells into the inguinal folds of nude mice. The tumors formed by miR-29ctransduced PANC cells were visibly smaller than the vector control tumors (Figure 3A). We used a stable
miRNA sponge strategy to inhibit miR-29c in vivo, and the inguinal tumors formed by miR-29c-spongetransduced cells were clearly larger than the sponge-vector control tumors. Moreover, immunoblotting showed that reintroducing miR-29c decreased the expression levels of multiple pluripotency-associated factors (CD24, CD44) and mesenchymal factor (vimentin) in vivo, while inhibiting miR-29c increased them, but the opposite was true for epithelial factor (E-cadherin) expression levels (Figure 3B). Our data validate the premise that reintroducing miR-29c suppresses the tumorigenic and invasive behavior of PANC in vivo.

\section{MiR-29c suppressed Wnt signaling}

The Wnt cascade has been recognized to play a critical role in regulating self-renewal and oncogenesis as well as metastasis $[25,26]$. We analyzed the expression of miR-29c and Wnt-regulated gene signatures via GSEA [27] in published PANC patient expression profiles, finding that miR-29c expression levels were inversely correlated with the Wnt-activated gene signatures and positively correlated with Wnt-suppressed gene signatures (Figure 4A). We next tested whether miR-29c suppressed Wnt signaling. $\beta$-Catenin/T cell factor (TCF) activity was significantly decreased in miR-29c-overexpressing PANC cells, but was increased in miR-29c-inhibited cells (Figure 4B). Furthermore, cellular fractionation showed that miR-29c overexpression decreased nuclear accumulation of $\beta$-catenin (Figure $4 \mathrm{C}$ ), indicating that miR-29c suppresses the Wnt/ $\beta$-catenin pathway by decreasing nuclear $\beta$-catenin accumulation. Real-time PCR analyses of miR-29c-overexpressing PANC cells
A

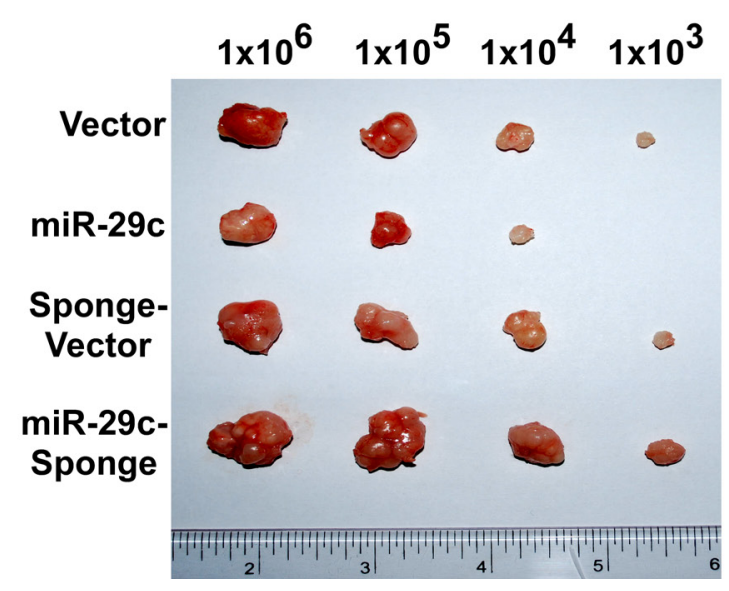

B

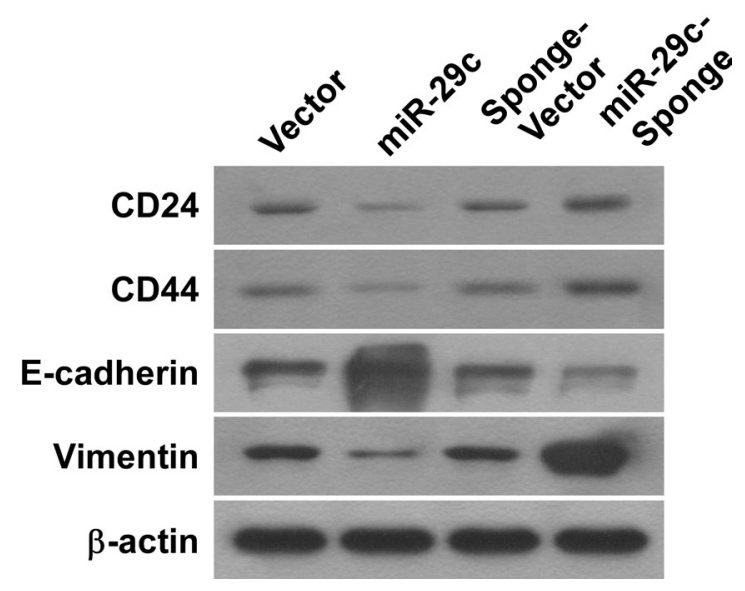

Figure 3: MiR-29c upregulation attenuated tumorigenicity and invasion in vivo. A, The tumors formed by miR-29c-transduced BxPC-3 cells were smaller than the vector control tumors. Conversely, the tumors formed by miR-29c-sponge-transduced BxPC-3 cells were larger than the tumors formed by the sponge-vector cells. Representative images of the tumors are shown. B, Western blot analysis of CD24, CD44, E-cadherin and vimentin expression in the indicated tissue samples. $\beta$-actin was used as a loading control. 
revealed that the expression levels of six classically recognized Wnt/ $\beta$-catenin target genes were remarkably decreased (Figure 4D). In summary, our findings indicate that miR-29c augments PANC tumorigenicity and invasion by suppressing Wnt signaling.

\section{MiR-29c directly suppressed Wnt cascade- activated regulatory genes}

As miRNAs exert their functions by targeting multiple transcripts, we screened for targets of miR29c using TargetScan, identifying four potential targets (FRAT2, LRP6, FZD4, FZD5) (Figure 5A). Immunoblotting analysis showed that miR-29c overexpression repressed FRAT2, LRP6, FZD4 and FZD5 expression levels, while miR-29c inhibition increased them (Figure 5B). The microribonucleoprotein immunoprecipitation and luciferase activity assays demonstrated that miR-29c associated directly with the 3' UTR of FRAT2, LRP6, FZD4 and FZD5 (Figure 5C, $5 \mathrm{D}$ and Supplementary Figure S1A, S1B). As FRAT2, $L R P 6, F Z D 4$ and FZD5 are the upstream regulatory genes of Wnt signaling, we assumed that exogenous $\beta$-catenin expression would restore the invasive and carcinogenic ability of miR-29c-overexpressing PANC cells, which our findings validated (Figure 5E, 5F). Taken together, our data show that miR-29c inhibits PANC tumorigenicity and invasion through direct suppression of multiple Wnt signaling core regulatory genes.

\section{TGF- $\beta$ /Smad3 signaling inhibited miR-29c in PANC}

We explored the molecular mechanism that mediates the reduction of miR-29c in PANC cells, using Genomic Identification of Significant Targets in Cancer (GISTIC) tools $[28,29]$ to identify copy number alterations (CNAs) in PANC tissues, but found no alteration in the miR-29c genomic region (Figure S2A). Furthermore, we assessed the methylation status of miR-29c in normal pancreatic tissues and PANC tissues by analyzing the publicly available data from TCGA (Figure S2B-a), finding that the methylation level detected by probe cy08855249 was higher in PANC tissues than in normal pancreatic tissues. Although the methylation level detected was inversely correlated with miR-29c expression levels (Figure S2B-b), it was not associated with PANC progression, which contradicted the earlier results (Figure 1B). Therefore, we suggest another mechanism reduces miR-29c in PANC. Additionally, GSEA showed remarkable correlation

A
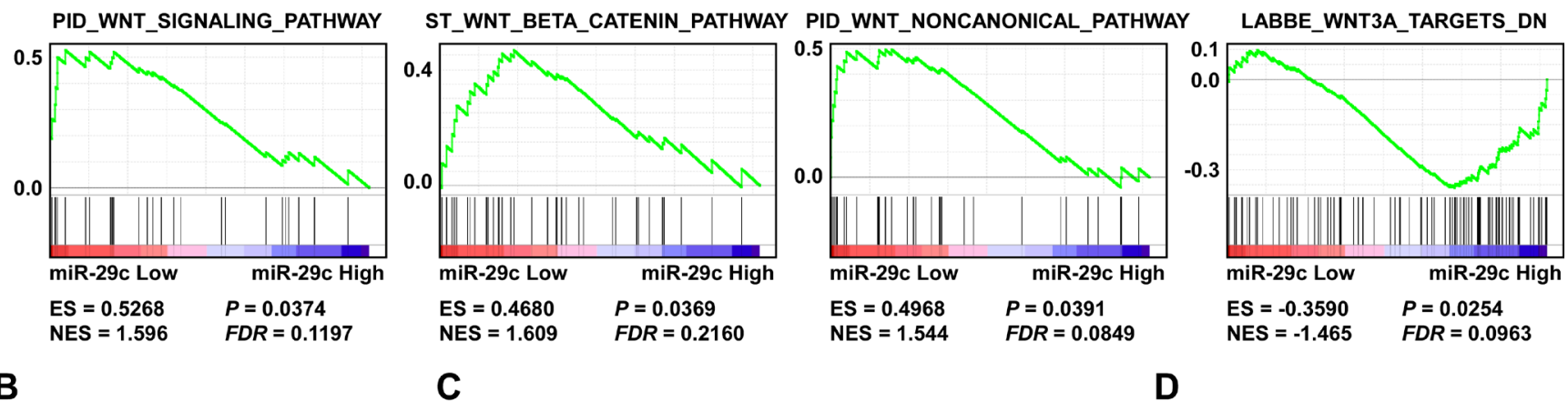

B
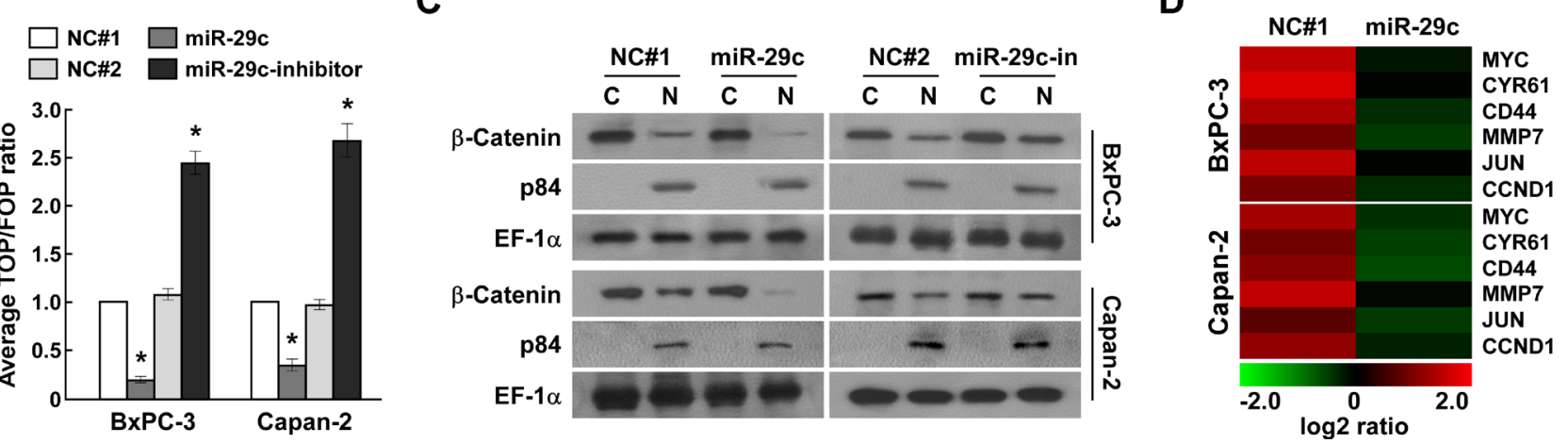

Figure 4: MiR-29c suppresses Wnt signaling. A, GSEA plot showing that miR-29c expression is inversely correlated with Wntactivated gene signatures and positively correlated with Wnt-suppressed gene signatures in published pancreatic cancer patient gene expression profiles (TCGA, $n=96$ ). B, TOP/FOP luciferase ratio reported Wnt/ $\beta$-catenin pathway activity in the indicated cells. C, Western blotting analysis of $\beta$-catenin expression in the cytoplasm $(\mathrm{C})$ and nucleus $(\mathrm{N})$ of the indicated cells. Nuclear protein p84 was used as a nuclear protein marker and EF-1 $\alpha$ as a loading control. D, Relative mRNA expression of Wnt/ $\beta$-catenin-regulated genes in the indicated cells was assessed by real-time PCR. GAPDH was used as a loading control. 
between miR-29c expression levels and the TGF- $\beta$ activated gene signatures (Figure 6A). Interestingly, TGF- $\beta / \mathrm{Smad} 3$ regulated miR-29 expression negatively [30]. The chromatin immunoprecipitation (ChIP) assay showed that endogenous Smad3 proteins bound to a sterol regulatory element (SRE) in the MIR29C promoter (Figure 6B); Figure 6C shows that miR-29c expression was decreased in PANC cells treated with TGF- $\beta$, but was increased in cells treated with a type I TGF- $\beta$ receptor inhibitor or a neutralizing anti-TGF- $\beta$ antibody. Furthermore, the luciferase activity of the Wnt signaling reporter was significantly increased in TGF- $\beta$-treated PANC cells, but was decreased in cells treated with a type

A

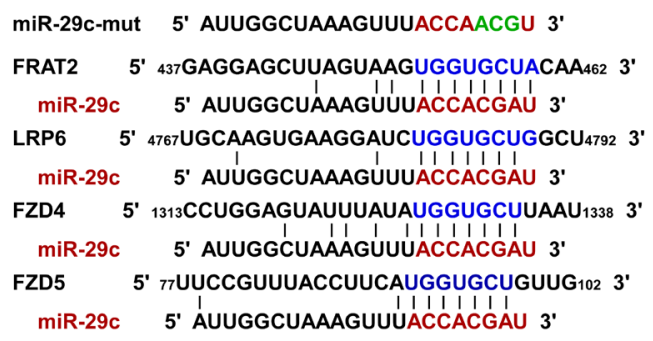

I TGF- $\beta$ receptor inhibitor or a neutralizing anti-TGF- $\beta$ antibody (Figure 6D). Collectively, our data confirm that the TGF- $\beta /$ Smad3 pathway decreases miR-29c expression by directly targeting the MIR29C promoter in PANC cells.

\section{MiR-29c expression correlated with Wnt cascade hyperactivation and Smad3 activity in clinical PANC}

We examined whether activation of the TGF- $\beta$ / Smad3/miR-29c/Wnt axis identified in our PANC cell models was also evident in clinical PANC. The miR29c levels in 10 freshly collected PANC samples were

B
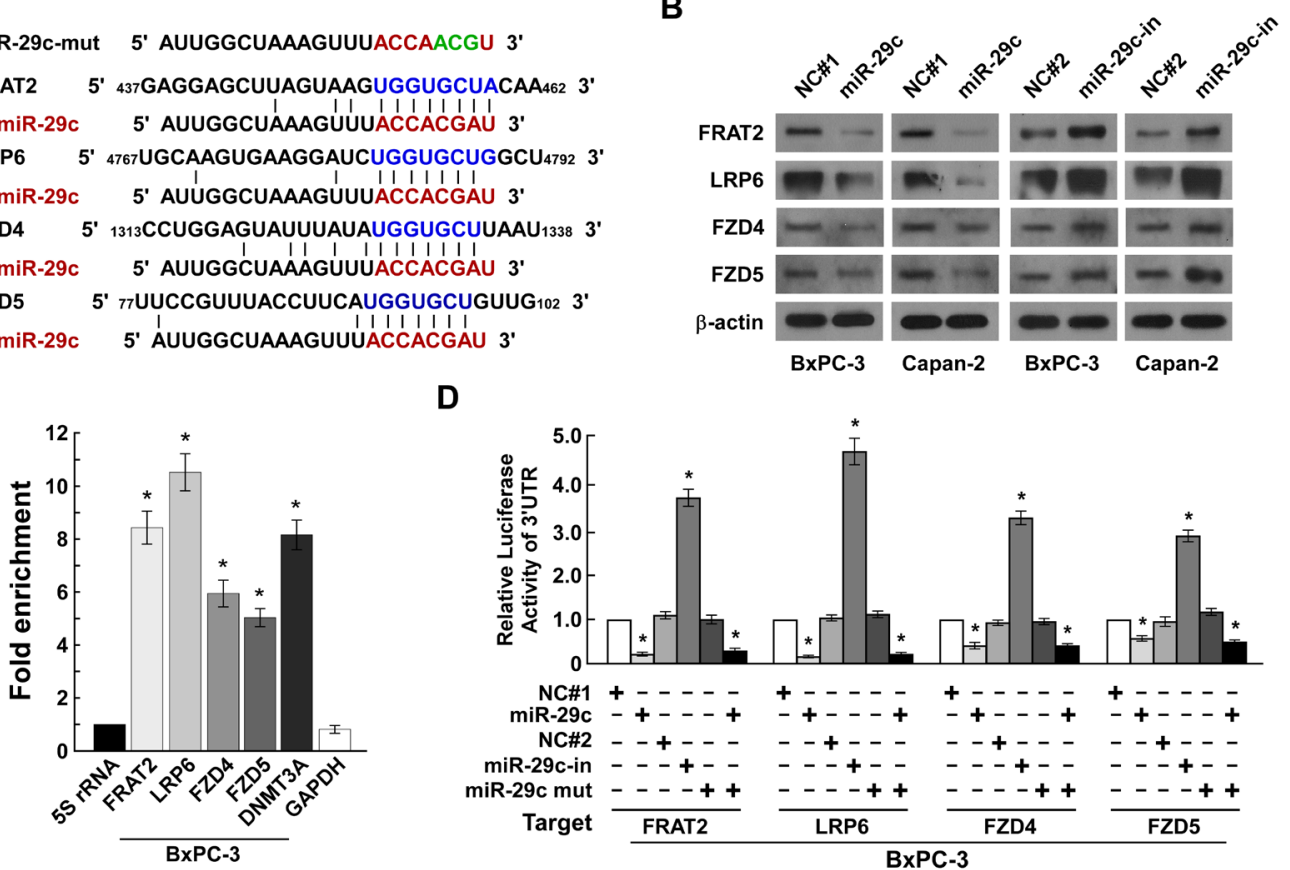

D

E

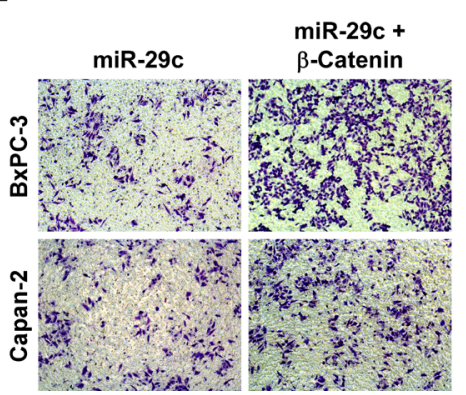

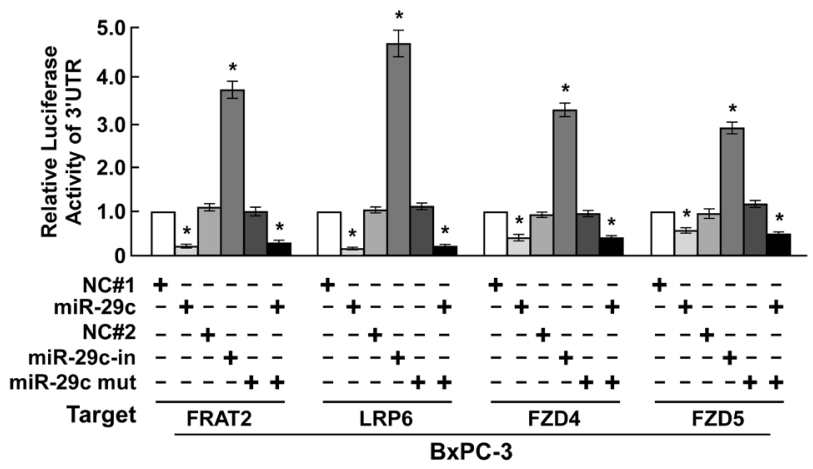

$\mathbf{F}$
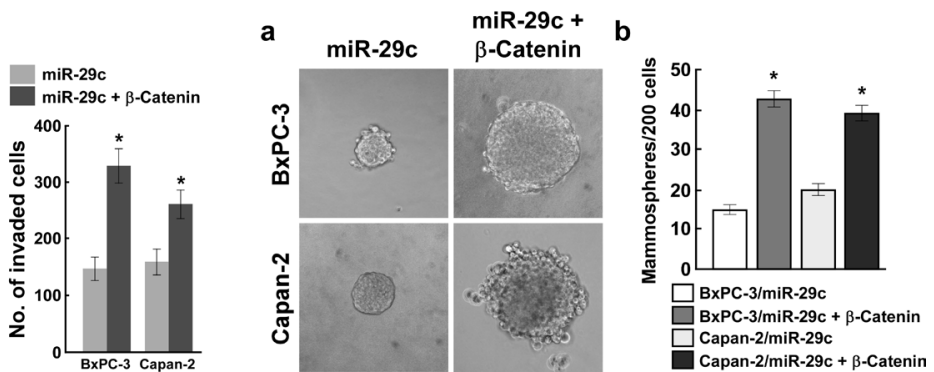

Figure 5: MiR-29c directly suppresses multiple Wnt cascade activate regulatory genes. A, Predicted miR-29c target sequences in FRAT2-3'UTR, LRP6-3'UTR, FZD4-3'UTR and FZD5-3'UTR. B, Western blot analysis of FRAT2, LRP6, FZD4 and FZD5 expression in the indicated cells. $\beta$-actin served as the loading control. C, miRNP IP assay showed association of miR-29c with FRAT2, LRP6, FZD4, FZD5, DNMT3A and GAPDH were used as positive and negative controls, respectively, and $5 S$ rRNA was used as a control for overall expression levels. D, Luciferase activities of FRAT2-3'UTR, LRP6-3'UTR, FZD4- 3'UTR or FZD5-3'UTR in vector- or miR$29 \mathrm{c}$-transduced cells, or in miR-29c-transduced cells transfected with miR-29c-mut, or in vector-transduced cells transfected with NC or miR-29c inhibitor. E, Representative images (left) and quantification (right) of penetrated cells were analyzed using the Transwell matrix penetration assay. F, Representative images of spheres formed by the indicated cells (left) and histograms showing the mean number of spheres (right). Error bars represent mean \pm SD from 3 independent experiments; * $P<0.05 ; * *, P<0.01$. 
inversely correlated with the mRNA levels of the following Wnt cascade downstream targets: MYC ( $r=$ -0.782, $P=0.008), C D 44(r=-0.810, P=0.004)$ and matrix metalloproteinase-7 (MMP-7, $r=-0.888, P=$ $0.001)$; and four bona fide targets of miR-29c: FRAT2 $(r$ $=-0.641 P=0.046)$, LRP6 $(r=-0.667, P=0.035)$, FZD4 $(r=-0.639, P=0.047)$ and FZD5 $(r=-0.734, P=0.016)$; and p-Smad3 $(r=-0.812, P=0.004)$ (Figure 6E). These data further support the notion that a hyperactive TGF- $\beta$ / Smad3 pathway suppresses miR-29c expression, resulting in Wnt signaling activation and the consequent promotion of malignant PANC phenotypes, high tumor recurrence rate and poor prognosis of clinical PANC.

\section{DISCUSSION}

An increasing amount of evidence shows that cancer treatments that fail to eradicate cancer stem cells (CSC) may lead to tumor recurrence, and these CSCs are implicated in tumor progression and metastasis, the critical causes of death in patients with cancer. Analysis of two public data sets revealed that miR-29c was decreased in patients who had died from PANC and in patients with proven tumor recurrence. We found that restoring miR29c suppressed Wnt signaling in PANC cells, attenuated cell migration and invasion and stem cell-like phenotypes in vitro and in vivo. Next, we demonstrated that FRAT2,
A

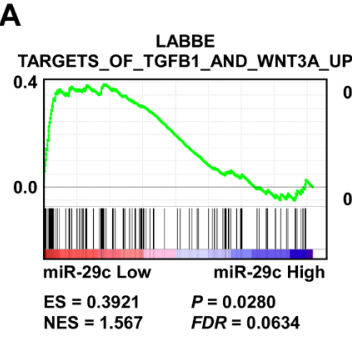

B

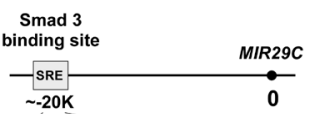

AAAGGTTTGTCAGTCTAGgGAATG

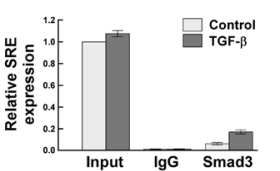

$\mathbf{E}$
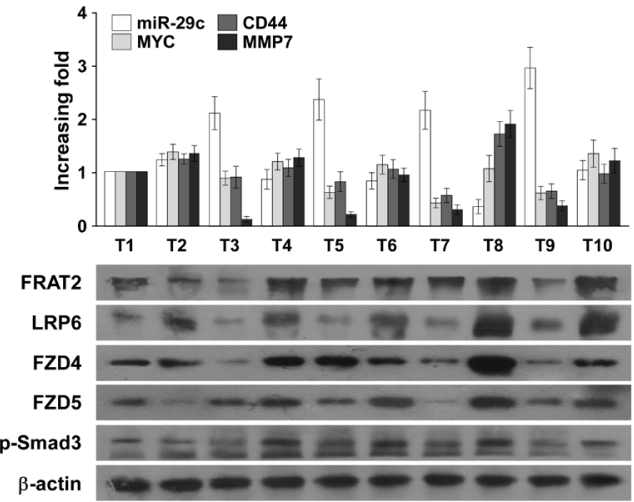

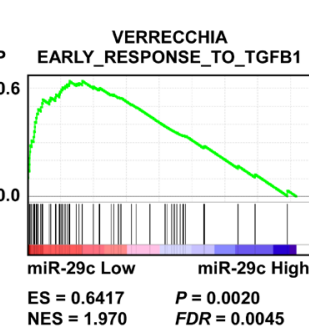

C

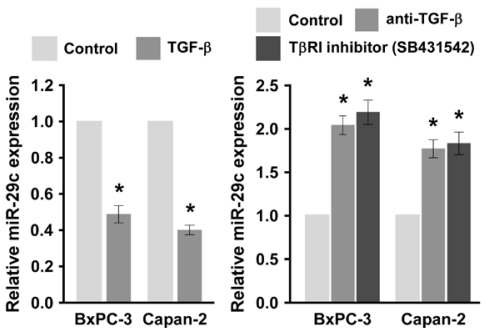

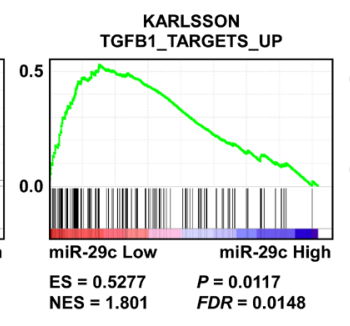

D
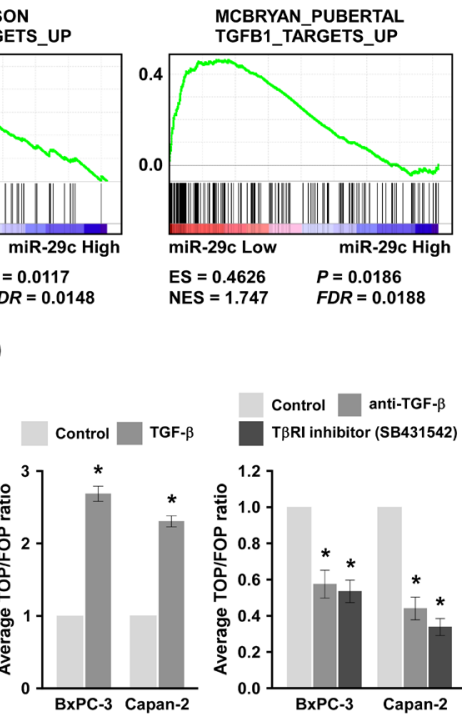
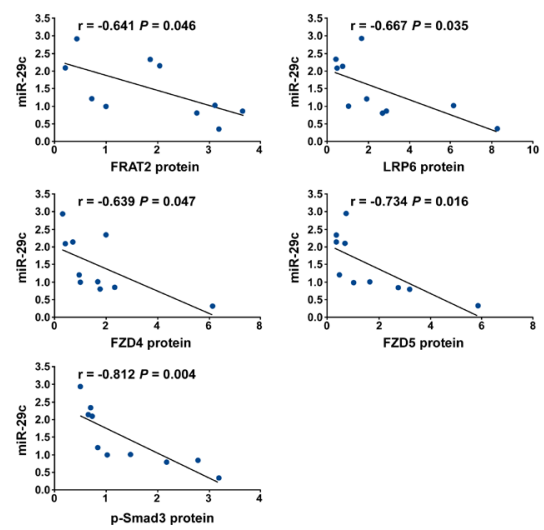

Figure 6: TGF- $\beta / \mathrm{Smad} 3$ inhibits miR-29c expression and clinical relevance of the TGF- $\beta / \mathrm{Smad} 3 / \mathrm{miR}-29 \mathrm{c} / \mathrm{Wnt}$ axis in pancreatic cancer. A, GSEA plot showing that miR-29c expression is inversely correlated with TGF- $\beta$-activated gene signatures in published pancreatic cancer patient gene expression profiles (TCGA, $n=96$ ). B, Schematic of typical SRE of the MIR29c promoter. Also shown are ChIP assay results for the SRE of MIR29c promoter physically associated with Smad3. C, Real-time PCR analysis of miR-29c expression in the indicated cells, either treated with 100 pM TGF- $\beta$ for 3 hours or treated with or without the T $\beta R I$ inhibitor $(2 \mu \mathrm{M})$ or a neutralizing anti-TGF- $\beta$ antibody $(2 \mu \mathrm{g} / \mathrm{ml})$ for 3 hours. Transcript levels were normalized by $U 6$ expression. D, TOP/FOP luciferase ratio reported Wnt/ $\beta$-catenin pathway activity in the indicated cells, either treated with $100 \mathrm{pM}$ TGF- $\beta$ for 3 hours or treated with or without the $\mathrm{T} \beta \mathrm{RI}$ inhibitor $(2 \mu \mathrm{M})$ or a neutralizing anti-TGF- $\beta$ antibody $(2 \mu \mathrm{g} / \mathrm{ml})$ for 3 hours. E, Expression and correlation of miR-29c with $C D 44$, $M Y C$, and MMP7 mRNA expression, as well as FRAT2, LRP6, FZD4, FZD5 and p-Smad3 protein expression in 10 freshly collected pancreatic cancer samples. 
LRP6, FZD4 and FZD5 are bona fide targets of miR-29c. Furthermore, we determined that TGF- $\beta /$ Smad 3 signaling decreased miR-29c expression levels in clinical PANC samples. To summarize our findings, our study reveals that miR-29c regulates PANC migration, invasion and stem cell-like phenotypes via a novel mechanism, i.e. by modulating multiple Wnt cascade regulators, intimating that miR-29c might function as a tumor-suppressive miRNA in human PANC.

Clearly, a better understanding of the critical pathways involved in migration, invasion and stem cell-like phenotypes is important for identifying new molecular targets to eradicate PANC. One particularly significant pathway shown to correlate with self-renewal and metastasis is the $\mathrm{Wnt} / \beta$-catenin signaling pathway. Indeed, more than $65 \%$ of pancreatic tumors show activation of the canonical Wnt/ $\beta$-catenin pathway [22]. It has also been reported that nuclear $\beta$-catenin and cyclin D1 are co-overexpressed in the invasion front of colorectal cancer $[31,32]$. In a breast cancer study, Lin and colleagues demonstrated that $\beta$-catenin modulated cyclin D1 expression [33]; later, Yook and associates found that the Wnt cascade regulates Snaill activity [34]. The Wnt cascade can be divided into the canonical and non-canonical pathways. It is noteworthy that canonical Wnt signaling has been proven to regulate stemness, proliferation and differentiation in several adult stem cell niches [35-37]. Canonical Wnt signaling targets the receptor complex consisting of FZD family receptors and the LRP5/6 co-receptor, inducing the assembly of a FZD-Disheveled (DVL) complex and LRP5/6-AXINFRAT complex, leading to the stabilization and nuclear accumulation of $\beta$-catenin. Then, nuclear $\beta$-catenin engages the $\mathrm{N}$-terminus of DNA-binding proteins of the TCF/lymphoid enhancing factor (LEF) family and modulates the transcription of a broad range of target genes. Although they have not been fully elucidated, several mechanisms activate the Wnt cascade, such as gene mutation, which interferes with $\beta$-catenin phosphorylation and ubiquitination [38-41], and the mutation-independent changes in the upstream effectors of $\beta$-catenin $[42,43]$. Herein, we found that miR-29c directly targeted and suppressed the expression of four $\beta$-catenin upstream effectors (FRAT2, LRP6, FZD4, FZD5), thereby suppressing Wnt signaling and leading to decreased PANC cell migration, invasion and stem cell-like phenotypes.

An abundant class of small non-protein-coding RNAs that function as negative gene regulators, miRNAs play important roles in multiple biological processes, such as cellular differentiation, proliferation, angiogenesis, invasion, metastasis and oncogenesis [44]. Mounting evidence has shown that miRNA dysregulation correlates with virtually all human cancers and indicates that miRNAs can function as either tumor suppressors or oncogenes. The miR-29 family members (miR29 a, miR-29b, miR-29c), which differ at their last few $3^{\prime}$ end nucleotides, act as tumor suppressors and are downregulated in human cancers, such as aggressive chronic lymphocytic leukemia [45], colon cancer [46], non-small cell lung cancer [47] and nasopharyngeal carcinoma [48]. Interestingly, whether members of the same miRNA family control similar biological events remains unclear [49]. Nagano and colleagues reported that miR-29a functions as an oncomiRNA by activating the Wnt cascade [50]. However, we believe that downregulated miR-29c plays important roles in PANC cells. Reducing miR-29c not only promoted PANC cell stemness, but also PANC cell migration and invasion abilities by suppressing Wnt cascade inhibition both in vitro and in vivo. Significantly, restoring miR-29c greatly abrogated PANC cell aggressiveness. Our findings provide compelling support indicating that members of the same miRNA family can control different biological events.

Lastly, we showed that TGF- $\beta / \mathrm{Smad} 3$ regulated miR-29c expression negatively by binding to the MIR29C promoter, leading to the loss of miR-29c in PANC cells. Analysis of previously published gene expression profiles from PANC tissues indicated that the miR-29c reduction was not correlated with CNA or with promoter methylation level. TGF- $\beta$ is a significant growth factor in PANC that promotes tumor growth and progression [51], and TGF- $\beta /$ Smad3 signaling promotes renal fibrosis by inhibiting miR-29 [30]. Moreover, the GSEA showed that the miR$29 \mathrm{c}$ expression levels were correlated with the TGF- $\beta$ activated gene signatures in PANC cells. In this context, we found that Smad3 binding to the MIR29C promoter led to reduced miR-29c expression in PANC cells.

In summary, great effort has been expended to clarify the mechanisms underlying the aggressive nature of PANC, and decades of research have focused on screening the effectors involved in tumor-related biological processes. In the present study, we identified miR-29c as a major mediator of two hallmarks of aggressive PANC: limitless replicative potential, and tissue invasion and metastasis. These effects were significantly associated with the repression of four $\beta$-catenin upstream effectors, i.e. FRAT2, LRP6, FZD4 and FZD5, resulting in constitutive activation of the Wnt cascade in PANC. Taken together, our study may provide new insights for understanding PANC cell migration and invasion as well as the stemness phenotype and therefore might contribute to future development of therapeutic interventions for this uniformly fatal disease.

\section{METHODS}

\section{Cell lines}

Normal pancrease cell line hTERT-HPNE and pancreatic cancer cell lines BxPC-3, Capan-1, Capan-2, 
HPAC, MIA PaCa-2, Panc 02.03, Panc 02.13 and PANC1 were from ATCC (Manassas, VA, USA). The cells were grown in Dulbecco's modified Eagle's medium supplemented with $10 \%$ fetal bovine serum.

\section{Plasmids, virus production, and target cell infection}

The human MIR29C gene was PCR-amplified from genomic DNA and cloned into a pMSCV-puro retroviral vector. MiR-29c sponge was constructed by annealing, purifying, and cloning oligonucleotides containing six tandem "bulged" miR-29c-binding motifs into the pMSCV vector. Human $\beta$-catenin were PCR-amplified from hTERT-HPNE complementary DNA (cDNA) and cloned into the pMSCV vector. The 3'UTRs of the human FRAT2 (FRAT2-3'UTR), LRP6 (LRP6-3'UTR), FZD4 (FZD43'UTR) and FZD5 (FZD5-3'UTR) genes, generated by PCR amplification from hTERT-HPNE, were cloned into the $S a c \mathrm{I} / X m a \mathrm{I}$ sites of pGL3 luciferase reporter plasmid (Promega, Madison, WI, USA). Plasmid transfection was performed using Lipofectamine 2000 (Invitrogen, Carlsbad, CA, USA) according to the manufacturer's instructions. Stable cell lines expressing miR-29c and miR-29c sponge were generated via retroviral infection using HEK293T cells as described by Li et al [52] and selected with $0.5 \mu \mathrm{g} / \mathrm{mL}$ puromycin for 10 days.

\section{Western blotting analysis}

Cells and tissues were harvested in sampling buffer [62.5 mmol/L Tris-HCl (pH 6.8), 10\% glycerol, 2\% sodium dodecyl sulfate (SDS)] and heated for 5 minutes at $100^{\circ} \mathrm{C}$. Protein concentration was determined with the Bradford assay using a commercial kit purchased from Bio-Rad Laboratories (Hercules, CA, USA). Equal quantities of protein were separated electrophoretically on $10 \% \mathrm{SDS} /$ polyacrylamide gels and transferred onto polyvinylidene difluoride membranes (Roche, Basel, Switzerland). The membranes were probed with diluted antibody. The expression of target proteins was determined with horseradish peroxidase-conjugated anti-rabbit immunoglobulin $\mathrm{G}$ ( $\mathrm{IgG}$ )/anti-mouse $\mathrm{IgG}$ (Sigma-Aldrich, St Louis, MO, USA) and enhanced chemiluminescence (Pierce, Rockford, IL, USA) according to the manufacturers' suggested protocols. The membranes were stripped and reprobed with an anti$\beta$-actin mouse monoclonal antibody (Sigma-Aldrich) as a loading control. The related antibodies were antiphosphorylated(p)-Smad3, anti-E-cadhernin, antiVimentin, anti- $\beta$-catenin (Cell Signaling Technology, Beverly, MA, USA), anti-CD24, anti-CD44, anti-CD166, anti-EpCam, anti-EF-1, anti-p84 anti-FRAT2, anti-LRP6, anti-FZD4, anti-FZD5 (Abcam, Cambridge, MA, USA) and anti-CD133 (Epitomics, USA).

\section{RNA extraction and real-time quantitative PCR}

Total miRNA from cultured cells and fresh surgical pancreatic cancer tissues was extracted using a mirVana miRNA Isolation Kit (Ambion, Foster City, CA, USA) according to the manufacturer's instructions. We synthesized cDNA using a TaqMan MicroRNA Reverse Transcription Kit (Applied Biosystems, Foster City, CA, USA) and quantified miR-29c expression using a miRNA-specific TaqMan MiRNA Assay Kit (Applied Biosystems). Real-time PCR was performed using the Applied Biosystems 7500 Sequence Detection System. MiRNA expression was defined based on the comparative threshold $(\mathrm{Ct})$; relative expression levels were calculated as $2^{\wedge}(\mathrm{Ct}$ miR-29c - Ct U6) after normalization with reference to the quantification of U6 small nuclear RNA expression.

\section{Microribonucleoprotein immunoprecipitation assay}

Cells were cotransfected with a plasmid that encodes hemagglutinin-tagged (HA)-Ago1 and miR-29c (100 nM), followed by HA-Ago1 immunoprecipitation (IP) using an anti-HA antibody. Real-time PCR analysis of the IP material was used to test the association of FRAT2, LRP6, FZD4, FZD5, DNMT3A and glyceraldehyde-3-phosphate dehydrogenase $(G A P D H)$ mRNA with the RNA-induced silencing complex.

\section{Luciferase assay}

Cells $\left(3 \times 10^{3}\right)$ were seeded in triplicate in 48well plates and allowed to settle for 24 hours. Luciferase reporter plasmids (100 ng) or $100 \mathrm{ng}$ control luciferase plasmid plus $1 \mathrm{ng}$ pRL-TK Renilla plasmid (Promega) were transfected into pancreatic cancer cells using Lipofectamine 2000 (Invitrogen). Luciferase and Renilla signals were determined 24 hours after transfection using a Dual Luciferase Reporter Assay Kit (Promega).

\section{Cell invasion assay}

Glioblastoma cells $\left(2 \times 10^{4}\right)$ were plated on the top side of a polycarbonate Transwell filter (with Matrigel) in the top chamber of a BioCoat Invasion Chamber (BD Biosciences, Bedford, MA, USA) and incubated at $37^{\circ} \mathrm{C}$ for 22 hours; cells in the top chamber were removed with cotton swabs. Cells that had migrated and invaded to the lower membrane surface were fixed in $1 \%$ paraformaldehyde, stained with hematoxylin, and counted under a microscope (10 random fields per well, $\times 100$ magnification). The cell counts were expressed as the mean number of cells per field. 


\section{Flow cytometric analysis}

Cells were dissociated with trypsin and resuspended at $1 \times 10^{6}$ cells per milliliter in DMEM containing $2 \%$ FBS and then preincubated at $37^{\circ} \mathrm{C}$ for 30 minutes with or without $100 \mu \mathrm{M}$ verapamil (Sigma-Aldrich) to inhibit $\mathrm{ABC}$ transporters. The cells were subsequently incubated for 90 minutes at $37^{\circ} \mathrm{C}$ with $5 \mu \mathrm{g} / \mathrm{ml}$ Hoechst 33342 (Sigma-Aldrich). Finally, the cells were incubated on ice for 10 minutes and washed with ice-cold PBS before flow cytometric analysis. The data were analyzed by Summit 5.2 software (Beckman Coulter).

\section{Tumor xenografts}

The nude mice were randomly divided into 4 groups $\left(\mathrm{n}=12\right.$ per group). Indicated cells of 4 dosages $\left(1 \times 10^{6}\right.$, $1 \times 105,1 \times 10^{4}, 1 \times 10^{3}$ ) were inoculated with Matrigel (final concentration of $25 \%$ ) into the inguinal folds of nude mice. The mice were scarified 31 days after inoculation and the tumors were excised and subjected to pathologic examination.

\section{Microarray data processing and visualization}

Microarray data were downloaded from The Cancer Genome Atlas (TCGA) database (http://cancergenome.nih. gov/). Analysis of miR-29c expression in PANC tissues compared with that in normal pancreas tissues was using a published microarray-based high-throughput assessment $(\mathrm{n}=148, P<0.001 ; \mathrm{NCBI} / \mathrm{GEO} / \mathrm{GSE} 24279)$. The data were downloaded from NCBI and analyzed using SPSS16.0 software. Gene Set Enrichment Analysis (GSEA) was performed using GSEA 2.0.9 (http://www.broadinstitute. org/gsea/).

\section{Statistics}

All statistical analyses were carried out using the SPSS 16.0 statistical software package (SPSS Inc., Chicago, IL, USA). The $\chi^{2}$ test was used to analyze the relationship between QKI expression and clinicopathological characteristics. Bivariate correlations between study variables were calculated by Spearman's rank correlation coefficients. $P<0.05$ was considered statistically significant.

\section{ACKNOWLEDGEMENTS}

This work was supported by grants from the National Natural Science Foundation of China (No. 81160311) and International Science \& Technology Cooperation Program of China(No.2014DFA31420).

\section{Conflict of Interest}

The authors declare that they have no conflict of interest.

\section{REFERENCES}

1. Stewart BW and Wild C. (2014). World cancer report 2014: World Health Organization).

2. Demols A, Peeters M, Polus M, Marechal R, Gay F, Monsaert E, Hendlisz A and Van Laethem JL. Gemcitabine and oxaliplatin (GEMOX) in gemcitabine refractory advanced pancreatic adenocarcinoma: a phase II study. Br J Cancer. 2006; 94(4):481-485.

3. Hernandez BY, Green MD, Cassel KD, Pobutsky AM, Vu $\mathrm{V}$ and Wilkens LR. Preview of Hawaii Cancer Facts and Figures 2010. Hawaii Med J. 2010; 69(9):223-224.

4. Bussom S and Saif MW. Methods and rationale for the early detection of pancreatic cancer. Highlights from the "2010 ASCO Gastrointestinal Cancers Symposium”. Orlando, FL, USA. January 22-24, 2010. JOP. 2010; 11(2):128-130.

5. Shahrokni A and Saif MW. Metastatic pancreatic cancer: the dilemma of quality vs. quantity of life. JOP. 2013; 14(4):391-394.

6. Bardou M and Le Ray I. Treatment of pancreatic cancer: A narrative review of cost-effectiveness studies. Best Pract Res Clin Gastroenterol. 2013; 27(6):881-892.

7. Kummermehr JC. Tumour stem cells--the evidence and the ambiguity. Acta Oncol. 2001; 40(8):981-988.

8. Reya T, Morrison SJ, Clarke MF and Weissman IL. Stem cells, cancer, and cancer stem cells. Nature. 2001; 414(6859):105-111.

9. Kuhn NZ and Tuan RS. Regulation of stemness and stem cell niche of mesenchymal stem cells: implications in tumorigenesis and metastasis. J Cell Physiol. 2010; 222(2):268-277.

10. Brabletz T, Jung A, Spaderna S, Hlubek F and Kirchner T. Opinion: migrating cancer stem cells - an integrated concept of malignant tumour progression. Nat Rev Cancer. 2005; 5(9):744-749.

11. Li C, Heidt DG, Dalerba P, Burant CF, Zhang L, Adsay V, Wicha M, Clarke MF and Simeone DM. Identification of pancreatic cancer stem cells. Cancer Res. 2007; 67(3):10301037.

12. Lee CJ, Dosch J and Simeone DM. Pancreatic cancer stem cells. J Clin Oncol. 2008; 26(17):2806-2812.

13. Hermann PC, Huber SL, Herrler T, Aicher A, Ellwart JW, Guba M, Bruns CJ and Heeschen C. Distinct populations of cancer stem cells determine tumor growth and metastatic activity in human pancreatic cancer. Cell Stem Cell. 2007; $1(3): 313-323$.

14. Visvader JE and Lindeman GJ. Cancer stem cells in solid tumours: accumulating evidence and unresolved questions. 
Nat Rev Cancer. 2008; 8(10):755-768.

15. Mueller MT, Hermann PC, Witthauer J, Rubio-Viqueira B, Leicht SF, Huber S, Ellwart JW, Mustafa M, Bartenstein P, D'Haese JG, Schoenberg MH, Berger F, Jauch KW, Hidalgo $\mathrm{M}$ and Heeschen C. Combined targeted treatment to eliminate tumorigenic cancer stem cells in human pancreatic cancer. Gastroenterology. 2009; 137(3):11021113.

16. Hammond SM. MicroRNAs as oncogenes. Curr Opin Genet Dev. 2006; 16(1):4-9.

17. Shimono Y, Zabala M, Cho RW, Lobo N, Dalerba P, Qian D, Diehn M, Liu H, Panula SP, Chiao E, Dirbas FM, Somlo G, Pera RA, Lao K and Clarke MF. Downregulation of miRNA-200c links breast cancer stem cells with normal stem cells. Cell. 2009; 138(3):592-603.

18. Liu C, Kelnar K, Liu B, Chen X, Calhoun-Davis T, Li H, Patrawala L, Yan H, Jeter C, Honorio S, Wiggins JF, Bader AG, Fagin R, Brown D and Tang DG. The microRNA miR34a inhibits prostate cancer stem cells and metastasis by directly repressing CD44. Nat Med. 2011; 17(2):211-215.

19. Ji J, Yamashita T, Budhu A, Forgues M, Jia HL, Li C, Deng C, Wauthier E, Reid LM, Ye QH, Qin LX, Yang W, Wang HY, Tang ZY, Croce CM and Wang XW. Identification of microRNA-181 by genome-wide screening as a critical player in EpCAM-positive hepatic cancer stem cells. Hepatology. 2009; 50(2):472-480.

20. Croce CM and Calin GA. miRNAs, cancer, and stem cell division. Cell. 2005; 122(1):6-7.

21. Reya $\mathrm{T}$ and Clevers $\mathrm{H}$. Wnt signalling in stem cells and cancer. Nature. 2005; 434(7035):843-850.

22. Zeng G, Germinaro M, Micsenyi A, Monga NK, Bell A, Sood A, Malhotra V, Sood N, Midda V, Monga DK, Kokkinakis DM and Monga SP. Aberrant Wnt/beta-catenin signaling in pancreatic adenocarcinoma. Neoplasia. 2006; 8(4):279-289.

23. Bauer AS, Keller A, Costello E, Greenhalf W, Bier M, Borries A, Beier M, Neoptolemos J, Buchler M, Werner J, Giese N and Hoheisel JD. Diagnosis of pancreatic ductal adenocarcinoma and chronic pancreatitis by measurement of microRNA abundance in blood and tissue. PLoS One. 2012; 7(4):e34151.

24. Wicha MS, Liu S and Dontu G. Cancer stem cells: an old idea--a paradigm shift. Cancer Res. 2006; 66(4):1883-1890; discussion 1895-1886.

25. DiMeo TA, Anderson K, Phadke P, Fan C, Perou CM, Naber $\mathrm{S}$ and Kuperwasser C. A novel lung metastasis signature links Wnt signaling with cancer cell self-renewal and epithelial-mesenchymal transition in basal-like breast cancer. Cancer Res. 2009; 69(13):5364-5373.

26. Chen G, Shukeir N, Potti A, Sircar K, Aprikian A, Goltzman D and Rabbani SA. Up-regulation of Wnt-1 and beta-catenin production in patients with advanced metastatic prostate carcinoma: potential pathogenetic and prognostic implications. Cancer. 2004; 101(6):1345-1356.
27. Subramanian A, Tamayo P, Mootha VK, Mukherjee S, Ebert BL, Gillette MA, Paulovich A, Pomeroy SL, Golub TR, Lander ES and Mesirov JP. Gene set enrichment analysis: a knowledge-based approach for interpreting genome-wide expression profiles. Proc Natl Acad Sci U S A. $2005 ; 102(43): 15545-15550$.

28. Mermel CH, Schumacher SE, Hill B, Meyerson ML, Beroukhim R and Getz G. GISTIC2.0 facilitates sensitive and confident localization of the targets of focal somatic copy-number alteration in human cancers. Genome Biol. 2011; 12(4):R41.

29. Beroukhim R, Mermel CH, Porter D, Wei G, Raychaudhuri S, Donovan J, Barretina J, Boehm JS, Dobson J, Urashima M, Mc Henry KT, Pinchback RM, Ligon AH, Cho YJ, Haery L, Greulich H, et al. The landscape of somatic copynumber alteration across human cancers. Nature. 2010; 463(7283):899-905.

30. Qin W, Chung AC, Huang XR, Meng XM, Hui DS, Yu CM, Sung JJ and Lan HY. TGF-beta/Smad3 signaling promotes renal fibrosis by inhibiting miR-29. J Am Soc Nephrol. 2011; 22(8):1462-1474.

31. Jung A, Schrauder M, Oswald U, Knoll C, Sellberg P, Palmqvist R, Niedobitek G, Brabletz T and Kirchner T. The invasion front of human colorectal adenocarcinomas shows co-localization of nuclear beta-catenin, cyclin D1, and $\mathrm{p} 16 \mathrm{INK} 4 \mathrm{~A}$ and is a region of low proliferation. Am $\mathrm{J}$ Pathol. 2001; 159(5):1613-1617.

32. Rasola A, Fassetta M, De Bacco F, D'Alessandro L, Gramaglia D, Di Renzo MF and Comoglio PM. A positive feedback loop between hepatocyte growth factor receptor and beta-catenin sustains colorectal cancer cell invasive growth. Oncogene. 2007; 26(7):1078-1087.

33. Lin SY, Xia W, Wang JC, Kwong KY, Spohn B, Wen Y, Pestell RG and Hung MC. Beta-catenin, a novel prognostic marker for breast cancer: its roles in cyclin D1 expression and cancer progression. Proc Natl Acad Sci U S A. 2000; 97(8):4262-4266.

34. Yook JI, Li XY, Ota I, Hu C, Kim HS, Kim NH, Cha SY, Ryu JK, Choi YJ, Kim J, Fearon ER and Weiss SJ. A WntAxin2-GSK3beta cascade regulates Snaill activity in breast cancer cells. Nat Cell Biol. 2006; 8(12):1398-1406.

35. Lowry WE, Blanpain C, Nowak JA, Guasch G, Lewis $\mathrm{L}$ and Fuchs E. Defining the impact of beta-catenin/Tcf transactivation on epithelial stem cells. Genes Dev. 2005; 19(13):1596-1611.

36. Woodward WA, Chen MS, Behbod F and Rosen JM. On mammary stem cells. J Cell Sci. 2005; 118(Pt 16):35853594.

37. Reya T, Duncan AW, Ailles L, Domen J, Scherer DC, Willert K, Hintz L, Nusse R and Weissman IL. A role for Wnt signalling in self-renewal of haematopoietic stem cells. Nature. 2003; 423(6938):409-414.

38. de La Coste A, Romagnolo B, Billuart P, Renard CA, Buendia MA, Soubrane O, Fabre M, Chelly J, Beldjord C, 
Kahn A and Perret C. Somatic mutations of the beta-catenin gene are frequent in mouse and human hepatocellular carcinomas. Proc Natl Acad Sci U S A. 1998; 95(15):88478851.

39. Hugh TJ, Dillon SA, O’Dowd G, Getty B, Pignatelli M, Poston GJ and Kinsella AR. beta-catenin expression in primary and metastatic colorectal carcinoma. Int J Cancer. 1999; 82(4):504-511.

40. He TC, Sparks AB, Rago C, Hermeking H, Zawel L, da Costa LT, Morin PJ, Vogelstein B and Kinzler KW. Identification of c-MYC as a target of the APC pathway. Science. 1998; 281(5382):1509-1512.

41. Morin PJ. beta-catenin signaling and cancer. Bioessays. 1999; 21(12):1021-1030.

42. Rimm DL, Caca K, Hu G, Harrison FB and Fearon ER. Frequent nuclear/cytoplasmic localization of beta-catenin without exon 3 mutations in malignant melanoma. Am J Pathol. 1999; 154(2):325-329.

43. Hsieh JC, Kodjabachian L, Rebbert ML, Rattner A, Smallwood PM, Samos CH, Nusse R, Dawid IB and Nathans J. A new secreted protein that binds to Wnt proteins and inhibits their activities. Nature. 1999; 398(6726):431436.

44. He L, Thomson JM, Hemann MT, Hernando-Monge E, $\mathrm{Mu}$ D, Goodson S, Powers S, Cordon-Cardo C, Lowe SW, Hannon GJ and Hammond SM. A microRNA polycistron as a potential human oncogene. Nature. 2005; 435(7043):828833.

45. Calin GA, Ferracin M, Cimmino A, Di Leva G, Shimizu M, Wojcik SE, Iorio MV, Visone R, Sever NI, Fabbri M, Iuliano R, Palumbo T, Pichiorri F, Roldo C, Garzon $\mathrm{R}$, Sevignani C, et al. A MicroRNA signature associated with prognosis and progression in chronic lymphocytic leukemia. N Engl J Med. 2005; 353(17):1793-1801.

46. Cummins JM, He Y, Leary RJ, Pagliarini R, Diaz LA, Jr., Sjoblom T, Barad O, Bentwich Z, Szafranska AE, Labourier E, Raymond CK, Roberts BS, Juhl H, Kinzler KW, Vogelstein B and Velculescu VE. The colorectal microRNAome. Proc Natl Acad Sci U S A. 2006; 103(10):3687-3692.

47. Fabbri M, Garzon R, Cimmino A, Liu Z, Zanesi N, Callegari E, Liu S, Alder H, Costinean S, FernandezCymering C, Volinia S, Guler G, Morrison CD, Chan KK, Marcucci G, Calin GA, et al. MicroRNA-29 family reverts aberrant methylation in lung cancer by targeting DNA methyltransferases 3A and 3B. Proc Natl Acad Sci U S A. 2007; 104(40):15805-15810.

48. Sengupta S, den Boon JA, Chen IH, Newton MA, Stanhope SA, Cheng YJ, Chen CJ, Hildesheim A, Sugden $\mathrm{B}$ and Ahlquist P. MicroRNA 29c is down-regulated in nasopharyngeal carcinomas, up-regulating mRNAs encoding extracellular matrix proteins. Proc Natl Acad Sci U S A. 2008; 105(15):5874-5878.

49. Esquela-Kerscher A and Slack FJ. Oncomirs - microRNAs with a role in cancer. Nat Rev Cancer. 2006; 6(4):259-269.

50. Nagano H, Tomimaru Y, Eguchi H, Hama N, Wada H, Kawamoto K, Kobayashi S, Mori M and Doki Y. MicroRNA-29a induces resistance to gemcitabine through the Wnt/beta-catenin signaling pathway in pancreatic cancer cells. Int J Oncol. 2013; 43(4):1066-1072.

51. Singh P, Wig JD and Srinivasan R. The Smad family and its role in pancreatic cancer. Indian J Cancer. 2011; 48(3):351360.

52. Li J, Zhang N, Song LB, Liao WT, Jiang LL, Gong LY, Wu J, Yuan J, Zhang HZ, Zeng MS and Li M. Astrocyte elevated gene-1 is a novel prognostic marker for breast cancer progression and overall patient survival. Clin Cancer Res. 2008; 14(11):3319-3326. 